\title{
Knowledge, Attitude and Practices of Breast Self-Examination Amongst Indian Women: A Pan-India Study
}

\author{
Shubhangini Sachdeva ${ }^{1}$, Sridhar Mangalesh ${ }^{2}$, Sharmila Dudani ${ }^{3}$
}

${ }^{1}$ Dr. D. Y. Patil Medical College, Pimpri, Maharashtra, India. ${ }^{2}$ Army College of Medical Sciences, Delhi Cantt, New Delhi, India. ${ }^{3}$ Department of Pathology, Army College of Medical Sciences, Delhi Cantt, New Delhi, India.

\begin{abstract}
Objective: Breast Cancer is the leading cause of mortality and morbidity amongst Indian females. Breast self-examination (BSE) as an early detection modularity can have a profound effect on lowering mortality, if it is practiced regularly. The aim of this study was to assess the knowledge, attitude, and practice of Breast Self-examination amongst Indian women, aged 30 years and above. Methods: A validated questionnaire, consisting 35 questions measuring 'Knowledge, Attitudes and Practice of Breast Self-Examination' was widely circulated amongst 1000 females throughout India and responses were collected for a duration of 3 weeks, from $2^{\text {nd }}$, September 2020 to $23^{\text {rd }}$,September 2020. Results: Despite having knowledge about the technique of performing BSE, the respondents did not have a positive attitude towards it and were reluctant to practice BSE. A total of 54.4\%, $15.1 \%, 21.3 \%$ and $9.2 \%$ of respondents were from the Northern, Southern, Western and Eastern regions of India, respectively. The overall median (IQR) KAP score was 70.0 (16.0) out of a maximum of 110. The knowledge, attitude and practice domain scores were 22.0 (5.0), 36.0 (7.0), and 13.0 (8.0) out of a maximum of 30, 52 and, 28 , respectively. All three individual score domains were significantly correlated with each other and the total score. Conclusion: Despite having knowledge about the technique of performing BSE, the respondents did not have a positive attitude towards it and were reluctant to practice BSE.
\end{abstract}

Keywords: Breast Cancer- Knowledge, Attitudes and Practice of Breast Self-Examination-Pan-India survey- BSE charting

Asian Pac J Cancer Care, 6 (2), 141-147

Submission Date: 10/22/2020Ａcceptance Date: 04/03/2021

\section{Introduction}

Breast Cancer ranks as the number one malignancy in Indian females, with an incidence of $27.7 \%$, accounting for $14 \%$ of cancers in this group [1-2]. It is also the leading cause of cancer related deaths amongst Indian females, with $11.1 \%$ of affected individuals succumbing to it [1].

In India, the incidence begins to rise in the early thirties and peaks between 50-64 years of age. In urban areas, 1 in 28 women is likely to develop breast cancer in her lifetime [3].

Worldwide, the primary tools used for early detection of the disease are Breast Self-Examination (BSE), Clinical Breast Examination (CBE) and Mammography. Proper and regular implementation of these is regarded as the main preventive strategy for breast cancer. BSE helps in early detection of breast cancer and can detect $40 \%$ of the breast lesions. Early detection of breast cancer has a positive correlation with a decreased morbidity and mortality, along with substantial healthcare savings [4].

The highest incidence of breast cancer, in India, is seen in cities like Delhi, Kolkata, Thiruvananthapuram, Bangalore, Mumbai as well as North-eastern states like Mizoram. Unlike the urban areas where it ranks as number one, in rural areas such as Barshi it still holds a second position [5-6]. Epidemiology of breast cancer across different Population Based Cancer Registries (PBCRs) in India shows increasing trends for incidence and mortality, mainly due to rapid urbanization, industrialization, population growth and increasing age [5]. In India, three states namely Kerala, Punjab and Tamil Nadu have the highest Disability Adjusted Life Years (DALY) rates for breast cancer [7]. According to the American Cancer Society recommendations for Early Detection of Breast

Corresponding Author:

Dr. Sharmila Dudani

Department of Pathology, Army College of Medical Sciences, Delhi Cantt, New Delhi, India.

Email:drsdudani@hotmail.com 
Cancer, every woman should know how her breasts look normally. She should be aware of their shape, size, and appearance so that she can notice any change in them, which might be an early sign of breast cancer. With this study, we hope to make a change in the attitude of Indian women regarding BSE. Along with it, impact the policy making process to promote BSE as the primary tool for early detection of Breast Cancer.

The main aim of this cross-sectional study was to assess the knowledge, attitude, and practice of Breast Self-examination amongst Indian women, aged 30 years and above.

\section{Materials and Methods}

\section{Data collection}

This pan-India, cross-sectional study was conducted by administering an online survey designed for assessing awareness regarding BSE amongst Indian women above the age of 30 years. A GoogleForms ${ }^{\circledR}$ adapted version of the validated questionnaire, 'Knowledge, Attitudes and Practice of Breast Self-Examination' by NH Nik Rosmawati was used [4]. It is a 35-item questionnaire used to analyse variables like age, profession and occupation with regard to knowledge, attitude and practice concerning BSE.

Ethical clearance was obtained prior to the commencement of our study. The survey was widely circulated throughout India and responses were collected for a duration of 3 weeks, from 2nd,September 2020 to 23rd,September 2020. Informed consent and approval for anonymized use of data for publication, was taken from all survey respondents. The sample size was calculated by taking a prevalence value of $50 \%$, precision $=4 \%, \alpha=0.05$ and a $95 \%$ confidence interval. The minimum required sample size was 601. 1042 responses were received. Of these, responses from pregnant females $(n=5)$, nursing mothers $(n=26)$ and breast cancer survivors $(n=11)$ were excluded. The final sample size was 1000 .

The questionnaire used, is divided into three parts by factor analysis. Questions (Q) 1-15 pertain to the knowledge domain including the methodology to perform BSE, (Q) 16-28 pertain to attitude regarding BSE and (Q) 29-35 pertain to the practice of BSE. True/False/ I do not know, were applied for the knowledge items. A 5-point Likert's scale was used for the responses regarding attitude and practice. The following responses, strongly agree/ agree/neutral/not agree/strongly not agree and never/ seldom/neutral/frequent/always, were applied to attitude and practice, respectively.

The following scoring method was used: for a positive knowledge item, '2' marks, '1' mark and '0' marks were allotted for a correct, I do not know and incorrect response, respectively. The scoring method was inversed for a negative knowledge item. For a positive attitude item, scores of '4', '3', '2', ' 1 ' and ' 0 ' were allotted for 'strongly agree', 'agree', 'neutral', 'disagree' and 'strongly disagree', respectively. The scoring was inversed for the negative attitude items. For a positive practice item scores of ' 0 ', ' 1 ', ' '2', '3' and '4' were assigned for 'never', 'seldom', 'neutral', 'frequently' and 'always', respectively. The scoring was inversed for a negative practice item. Participants who scored above and below $70 \%$ on any given section of the questionnaire, were considered to have 'good' or 'poor' knowledge, attitudes, or practices, respectively.

Demographic parameters like age, highest degree of education, profession, current residence, native residence, marital and parity status, family history of breast cancer, pregnancy, and current breastfeeding status, were also recorded.

\section{Statistical Analysis}

Statistical analysis was performed on the IBM statistical package for the social sciences (SPSS) for Window, Version 24.0 (Armonk, NY: IBM Corp). Continuous data is expressed as Median \pm Interquartile range (IQR). Categorical variables are expressed as percentage with $95 \%$ confidence interval (CI). Normality of continuous measures was assessed using the Shapiro-Wilk test and homogeneity of variances using Levene's test. Comparison of groups was done using the Kruskal Wallis test. Correlation coefficients were calculated for two continuous variables using the Spearman correlation. Categorical variables were compared using a Chi-Square test. A p-value of $<0.05$ was taken to be statistically significant.

\section{Results}

This study consisted of 1000 survey respondents. A total of $54.4 \%, 15.1 \%, 21.3 \%$ and $9.2 \%$ of respondents were from the Northern, Southern, Western and Eastern regions of India, respectively. The overall median (IQR) KAP score was 70.0 (16.0) out of a maximum of 110 . The knowledge, attitude and practice domain scores were 22.0 (5.0), 36.0 (7.0), and 13.0 (8.0) out of a maximum of 30,52 and, 28, respectively. All three individual score domains were significantly correlated with each other and the total score (Table 1).

Demographic variables of age, education, and

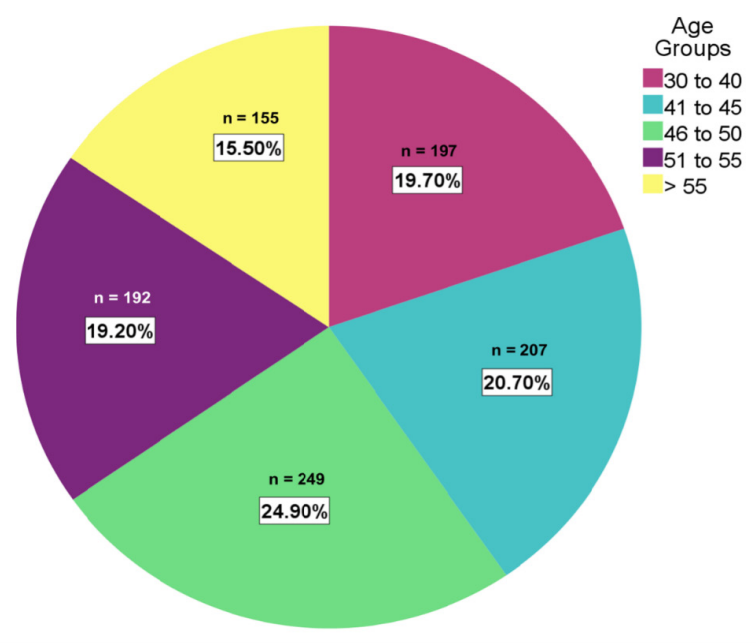

Figure 1. Age Distribution of Study Participants 
Table 1. Correlation between Domain Scores

\begin{tabular}{llccc}
\hline Score & & Knowledge & Attitudes & Practices \\
\hline Total KAP & Correlation & 0.622 & 0.783 & 0.835 \\
& Significance & $<0.0001$ & $<0.0001$ & $<0.0001$ \\
Knowledge & Correlation & -- & 0.282 & 0.347 \\
& Significance & & $<0.0001$ & $<0.0001$ \\
Attitudes & Correlation & 0.282 & --- & 0.469 \\
& Significance & $<0.0001$ & & $<0.0001$ \\
\hline
\end{tabular}

occupation are presented in Table 2. Survey respondents predominantly had a postgraduate or an undergraduate level of education, and others included senior secondary, high-school, diplomas, or vocational training. Most respondents were homemakers and educators. Other occupations included designers, lawyers, architects, journalists, etc (Figure 1, Figure 2 and Figure 3).

The K, A, P and total KAP scores were fairly equal for participants residing in different cities.

There was no statistically significant difference in KAP or individual domain scores between the different age groups (Table 3).

Postgraduates and undergraduates had significantly higher knowledge domain, attitudes domain, and total KAP scores than those with a lesser level of education. On doing pairwise comparisons, postgraduates had significantly higher knowledge domain scores compared to undergraduates, but no significant difference emerged for the other scores. The results are summarized in (Table 4).

Medical professionals had significantly higher scores in all three domains, as well as, total KAP scores, compared to all other occupations. On pairwise comparisons, medical professionals had significantly

Table 2. The Demographic and Socioeconomic Distribution of Responders

\begin{tabular}{lcc}
\hline Variable & Number & Percent \\
\hline Age (in years) & & \\
$30-40$ & 197 & 19.7 \\
$41-45$ & 207 & 20.7 \\
$46-50$ & 249 & 24.9 \\
$51-55$ & 192 & 19.2 \\
$>55$ & 155 & 15.5 \\
Education & & \\
Post graduate & 630 & 63.0 \\
Graduate & 326 & 32.60 \\
Other & 44 & 4.4 \\
Occupation & & \\
Home-maker & 290 & $29.0 \%$ \\
Educator/Teacher & 236 & 23.6 \\
Self Employed & 152 & 15.2 \\
Medical professional & 89 & 8.9 \\
IT and related professionals & 59 & 5.9 \\
Others & 174 & 17.4 \\
\hline
\end{tabular}

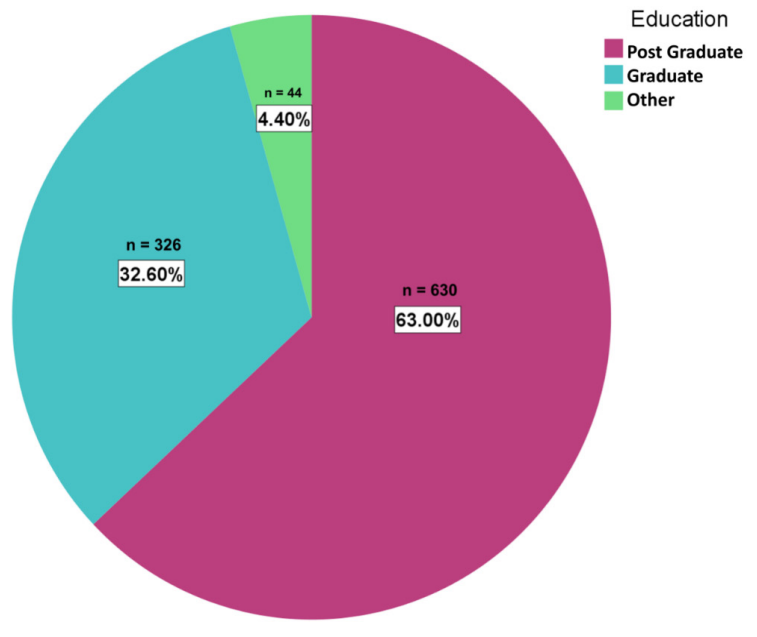

Figure 2. Levels of Education among Study Participants

higher scores than all other occupations, and no significant differences in scores emerged between any of the other occupations. Results are summarized in (Table 5).

A total of $210(21 \%)$ respondents had a positive family history of breast cancer. Amongst them, 59 (28.1\%) reported breast cancer in their mothers, $17(0.08 \%)$ in a sister, $87(41.4 \%)$ in an aunt, and $65(30.9 \%)$ in some other blood relative. Those with a positive family history of breast cancer were more likely to have a good knowledge domain score and total KAP score, compared to those who did not have a family history of breast cancer (Table 5).

\section{Discussion}

The present study constituted of 1000 participants who were categorized according to their age, level of education and occupation. The Knowledge (K), Attitudes (A), Practice (P) and total KAP scores were calculated.

A positive correlation between knowledge, attitude, practice scores and total KAP score was found. Individual score domains were also positively correlated with each other. (Table 1).

Our findings indicate that the knowledge score [ 22 on a total of 30] for the population under study was good. However, the attitude score [36 on a total of 52] and the practice [13 on a total of 28] score, both were poor. The low average scores of attitude and practice, consequently brought down the average KAP score. It was noted that despite having knowledge about the technique of 
Table 3. Median Knowledge, Attitudes, Practices, and Total Scores Across Age Groups

\begin{tabular}{lcccccc}
\hline Age Groups & $\begin{array}{c}30-40 \\
(\mathrm{n}=197)\end{array}$ & $\begin{array}{c}41-45 \\
(\mathrm{n}=207)\end{array}$ & $\begin{array}{c}46-50 \\
(\mathrm{n}=249)\end{array}$ & $\begin{array}{c}51-55 \\
(\mathrm{n}=192)\end{array}$ & $\begin{array}{c}>55 \\
(\mathrm{n}=155)\end{array}$ & P-Value* \\
\hline Knowledge & $22(5)$ & $22(5)$ & $23(5)$ & $23(5)$ & $23(5)$ & 0.11 \\
Attitudes & $35(6)$ & $36(8)$ & $36(7)$ & $36(7.75)$ & $36(7)$ & 0.188 \\
Practices & $12(8)$ & $13(10)$ & $13(8)$ & $13(10)$ & $12(8)$ & 0.54 \\
Total KAP & $68(16)$ & $71(15)$ & $72(14.5)$ & $70(17)$ & $72(16)$ & 0.127 \\
\hline
\end{tabular}

*Kruskal Wallis Test

Table 4. Median Knowledge, Attitudes, Practices, and Total Scores Across Education Groups

\begin{tabular}{lcccc}
\hline Education & $\begin{array}{c}\text { Postgraduate } \\
(\mathrm{n}=630)\end{array}$ & $\begin{array}{c}\text { Undergraduate } \\
(\mathrm{n}=326)\end{array}$ & $\begin{array}{c}\text { Others } \\
(\mathrm{n}=44)\end{array}$ & P-Value* \\
\hline Knowledge & $23(5)$ & $22(5)$ & $20(5)$ & $<0.0001$ \\
Attitudes & $36(8)$ & $36(7)$ & $32(8.75)$ & $<0.0001$ \\
Practices & $13(8)$ & $12(9)$ & $10.5(7.75)$ & 0.1086 \\
Total KAP & $71(14.25)$ & $70(17)$ & $63(13.75)$ & $<0.0001$ \\
\hline
\end{tabular}

*Kruskal

performing BSE, the respondents did not have a positive attitude towards it. Survey respondents also displayed a certain reluctance in practicing BSE, as the practice score was extremely poor. These findings were consistent with previously done studies, where high knowledge scores were correlated with low practice scores [4,8-10]. However, studies conducted in Malaysia, Pakistan and, India depicted that the women under observation had low $\mathrm{K}$ and $\mathrm{P}$ scores but a high A score $[4,11,12]$. This shows that knowledge and practice are linked positively, as also concluded by two isolated studies done in Turkey and Korea [13-14]. A study conducted in the Silicon Valley of India demonstrated that the women had a higher P score, but low $\mathrm{K}$ and A scores [15].

Our study highlights three important reasons for a poor practice score. The major one being that $67.2 \%$ of these 1000 women, had never been taught BSE by the health care staff. This calls for attention to the serious need of mandatorily introducing BSE programmes by trained health care workers. A Turkish study concluded that nurses as health care professionals could play a key role in educating women about BSE [16]. Programmes aimed at targeting small groups of women at the community level need to be encouraged, which not only disseminate the correct knowledge and technique about BSE under supervision, but also ensure comfort and privacy to the individual. Peer group interactions would also instil a positive attitude regarding BSE.
Our study found that, $62.1 \%$ of our participants did not conduct BSE even once a month, as is recommended by Johns Hopkins University, Maryland. A similar result was found in previous studies [4,15-18]. The various reasons implicated for a poor practice score were below par knowledge, inadequate emphasis by the doctor, poor regard for one's own health and underestimation of the risk associated with having cancer. To overcome this, the technique of 'BSE charting', similar to menstrual cycle charting can be introduced, which will ensure that BSE is conducted every month at the end of each menstrual cycle. In this age of digitalization, the use of BSE reminder applications should also be encouraged. Another reason for a low practice score was the lack of parental and partner support, which was documented by $54 \%$ of the respondents. The Indian social fabric ingrains the women from a young age to put her familys health care needs above her own. Thus, a change in attitude is warranted. With rapid urbanisation and globalisation, India is seeing a surge in non-communicable diseases, including cancer. Therefore, it is to empower urban Indian women to be more proactive and responsible for their own health and well-being.

Another possible reason, for the gap in their knowledge and practice can be attributed to the hectic pace of urban city life, as $49.7 \%$ respondents were residents of large urban metropolises. Out of the 1000 participants, $71 \%$ were working women. Imbalance between

Table 5. Median Knowledge, Attitudes, Practices, and Total Scores Across Occupation Groups

\begin{tabular}{lccccccc}
\hline Occupation & Homemaker & $\begin{array}{c}\text { Educators/ } \\
\text { Teachers Professors }\end{array}$ & Self Employed & $\begin{array}{c}\text { Medical } \\
\text { Professionals } \\
(\mathrm{n}=89)\end{array}$ & $\begin{array}{c}\text { IT and Related } \\
\text { Professions } \\
(\mathrm{n}=59)\end{array}$ & Other & P-Value* \\
& $(\mathrm{n}=290)$ & $(\mathrm{n}=236)$ & $(\mathrm{n}=152)$ & $174)$ & \\
\hline Knowledge & $22(4)$ & $23(5)$ & $22(4)$ & $24(5)$ & $22(6)$ & $23(5)$ & $<0.0001$ \\
Attitudes & $35(6)$ & $36(7)$ & $35(7)$ & $38(8)$ & $36(8)$ & $36(8)$ & $<0.0001$ \\
Practices & $13(8)$ & $13(8)$ & $11(7.75)$ & $18(8)$ & $12(8)$ & $11(7)$ & $<0.0001$ \\
Total KAP & $70(15)$ & $71(15.75)$ & $68(16.75)$ & $82(15)$ & $69(14)$ & $70(16)$ & $<0.0001$ \\
\hline
\end{tabular}

*Kruskal Wallis Test 
Table 6. Association of Knowledge, Attitudes, Practices, and Total Scores with Family History of Breast Cancer

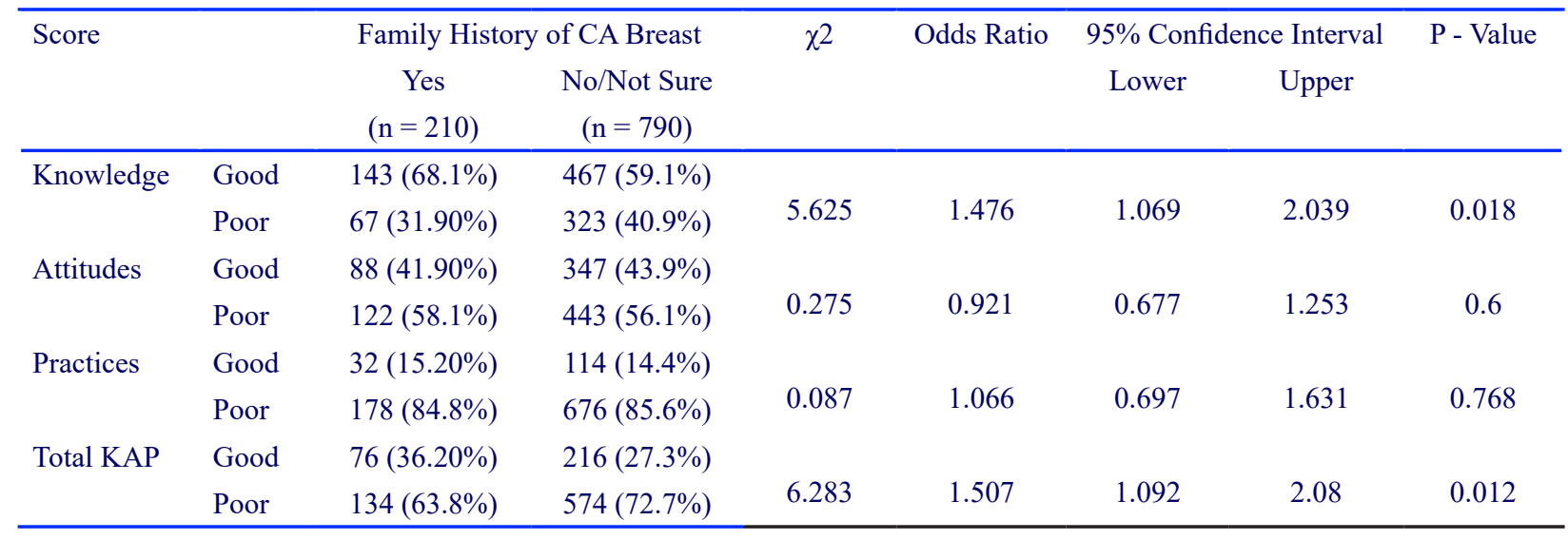

their professional and personal life, a busy lifestyle, self-negligence, and complacency could all be reasons for this wide gap. It was alarming to see that a barely noticeable difference existed between the metropolises and other cities. Breast related health is still a taboo, especially in a country like India, where the socio-cultural attitudes are not progressive. Thus, shyness related to one's body, rejection from their partner post diagnosis of breast cancer, discomfort and embarrassment in examining their breasts and lack of support may be the underlying reasons.

The incidence of breast cancer is known to progress with increasing age. Traditionally, one would expect that the $\mathrm{K}, \mathrm{A}, \mathrm{P}$ and total KAP scores would demonstrate a similar rise, with the increasing age of the woman. A previously conducted study in Great Britain, concluded that women seriously lacked knowledge about the 'age pattern' of breast cancer risk and only $1 \%$ women were aware about the escalating risk of breast cancer with increasing age [19]. In our study, there was no statistically significant difference found between the individual score domains $(\mathrm{K}, \mathrm{A}, \mathrm{P})$ and the total KAP score in the different age groups (Table 3 ). This was consistent with a study done by Parsa et al [20]. However, a study done by Huguley and Brown stated that the practice of BSE decreased, with increasing age [21]. Studies done in different parts of the world, concluded that both knowledge and practice of BSE was positively correlated with increasing age. More specifically, women above the age of 40 years were more likely to have better knowledge and implementation of

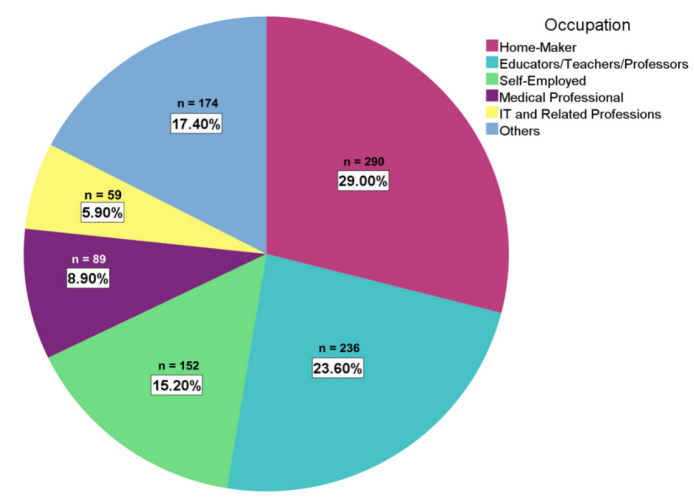

Figure 3. Occupations of Study Participants

\section{BSE [22-24].}

It was found that participants with a post-graduate and under-graduate degree qualification had higher knowledge and total KAP scores, as compared to those without a degree level of education (Table 4). This result was consistent with the findings of previous studies, which confirmed that a higher education conferred better knowledge and practice of BSE [25-26]. It was observed that, a high knowledge score brought up the total KAP score. This trend can be used to increase the penetration of practice of BSE, to benefit society. Health care workers and females with a reasonable level of education, armed with appropriate training can help in the dissemination of information amongst their own family, friends and peer groups. They can also act as mentors to individuals at a higher risk.

BSE needs to be made an integral part of the education system from the high school level itself which may lead to an increase in the knowledge scores and promotion of a healthy attitude towards the practice of BSE.

The attitude scores of the post-graduate and under-graduate participants were identical, but still higher than those without a degree level of education. Hence, not only does higher education have an impact on the level of knowledge, it also encourages a more positive attitude towards BSE.

There was no statistically significant difference found in the practice scores between the different groups divided on-the-basis of education. This was consistent with a previously conducted study [24].

A statistically significant difference existed for knowledge, attitude, practice and total KAP scores amongst different occupational groups (Table 5). We concluded that medical related professionals had a notably higher individual domain as well as total KAP scores, as compared to women in other professions. This was consistent with the findings of previously done studies [27]. Our study suggests, that being a healthcare professional confers a certain advantage about awareness of BSE. A general consciousness towards ones' health, more opportunities to come across breast related illnesses and a higher level of education could all be reasons for this disparity between medical professionals and other occupational groups. This finding was contrary to a study 
done in Hyderabad, India which concluded that despite having a medical background, the individual domain, and overall scores, both were low in the selected study group [28].

To curb this gap between the medical and other professions, educational programmes about BSE should be made mandatory for all women. Campaigns and movements, which not only educate about the correct technique of BSE but also promote a healthy attitude and practice towards it, should be held at regular intervals. Women should be emboldened to participate along with their partners and parents.

Patients' with a positive history of breast cancer had a significantly higher knowledge, as compared to women who did not have a family history of breast cancer (Table 6). However, alarmingly, and contrary to what was anticipated, these women had lower attitude, practice and total KAP scores than women with a negative family history of breast cancer. This exhibited that even though these women, who had a relative with breast cancer, were well-aware about the method of doing BSE, they not only lagged in its practice but also did not have a constructive attitude towards it. These results were consistent with a study conducted in Malaysia, which concluded that there was no correlation between BSE behaviour and family history of breast cancer [20]. Contact tracing to target the first and second degree relatives of the breast cancer patient by health centres, may help promulgate the concept of BSE in a high risk population. Follow-up visits every year should be encouraged by the health care staff.

This study concludes that a poor attitude towards BSE is a big barrier between the knowledge and practice of BSE. A change in attitude, by publicising the concept of BSE is the need of the hour. This can only be accomplished by a multifaceted approach. The involvement of the public is equally important, to partner along with the government and various not for profit non-governmental organizations (NGOs). Usage of advertisements, mass media, infomercials and brochures should also be encouraged. Wide-spread use of illustrative posters in local languages along with interactive sessions by health care workers are required for disseminating information about BSE. Previously done studies have highlighted the role of health care staff and media in dissemination of information [11,28-30].

BSE needs to be encouraged in a country like India, where there is a huge disparity in the delivery of health care across the country. India, though an emerging economy, still does not have the infrastructure and resources to make modern technology for early detection of breast cancer, be easily made available across the country. The prohibitive cost too, makes it out of reach for the common woman. Unlike India, most developed nations have structured preventive health care programs, which include mammograms for women above the age of 35 years. Thus, in a resource poor, third world country like India, BSE becomes singularly important and can serve as a simple, cost-effective, and self-sufficient tool for the early detection of breast cancer. National programs, aimed at popularizing BSE, need to be introduced to reduce the morbidity and mortality associated with breast cancer. The barriers of low levels of education as well as a poor socio-economic status can be overcome by BSE, as it does not require any additional resources. It can also be viewed as tool for women empowerment.

\section{Limitations}

This is a cross-sectional study and therefore causal conclusions cannot be drawn. This study specifically targets the urban female population of India, with a certain level of education, who know how to read and speak English. Thus, it is not a representation of the rural strata. Even though breast cancer increases with age, this study does not include a significant number of senior citizens possibly due to decreased use of smart phones and computers by which this survey was circulated. Mizoram, a north eastern state in India, ranks fifth globally for highest incidence of breast cancer. However, adequate number of responses could not be collected from that region. Although, few ethnic groups evince a higher incidence of breast cancer, the ethnicity of the respondents could not be verified. Hence, the variance of individual domain and total KAP scores with ethnicity could not be studied.

\section{Role of Funding}

This research did not receive any specific grant from funding agencies in the public, commercial, or not-forprofit sectors.

\section{Authors Contributions}

All authors have participated and contributed equally to literature search, study design, data collection, data analysis, data interpretation, writing of this article and revising it for important intellectual content and have given final approval for the version to be submitted. All authors have accessed and verified the underlying data.

\section{Conflicts of Interest}

The authors declare no conflict of interest.

\section{Ethics Committee Approval}

Institutional Ethical Committee approval was obtained prior to the conduction of this study.

\section{References}

1. WHO certified fact sheet. Globocan 2018, International Agency for Research on Cancer. https:/gco.iarc.fr/today/ data/factsheets/populations/356-india-fact-sheets.pd [Accessed 25 September 2020].

2. Ferlay J, Soerjomataram I, Dikshit R, Eser S, Mathers C, Rebelo M, Parkin DM, Forman D, Bray F. Cancer incidence and mortality worldwide: Sources, methods and major patterns in GLOBOCAN 2012. International Journal of Cancer. 2014 Oct 09;136(5):E359-E386. https://doi. org/10.1002/ijc. 29210

3. Globocan 2018 Cancer Statistics. National Institute of Cancer Prevention and Research, Indian Council of Medical Research. 2018 http://cancerindia.org.in/cancer-statistics/ [Accessed 25 September 2020]. 
4. Rosmawati N. Knowledge, attitudes, and practice of breast self-examination among women in a suburban area in Terengganu, Malaysia. Asian Pac J Cancer Prev. 2010;11:1503-8

5. Malvia S, Bagadi SA, Dubey US, Saxena S. Epidemiology of breast cancer in Indian women. Asia-Pacific Journal of Clinical Oncology. 201702 09;13(4):289-295. https://doi. org/10.1111/ajco.12661

6. Mudur G. India has some of the highest cancer rates in the world. BMJ. 200501 27;330(7485):215.4. https://doi. org/10.1136/bmj.330.7485.215-c

7. Dhillon PK, Mathur P, Nandakumar A, Fitzmaurice C, Kumar GA, Mehrotra R, Shukla DK, et al. The burden of cancers and their variations across the states of India: the Global Burden of Disease Study 1990-2016. The Lancet Oncology. 2018 Oct;19(10):1289-1306. https://doi.org/10.1016/s14702045(18)30447-9

8. Nwagbo D, Akpala C. Awareness of breast cancer and breast self-examination among women in Enugu urban Eastern Nigeria. 1996;1:34-6.

9. Chie W, Cheng K, Fu C, Yen L. A Study on Women's Practice of Breast Self-Examination in Taiwan. Preventive Medicine. 1993 05;22(3):316-324. https://doi.org/10.1006/ pmed.1993.1026

10. Mazzini CB. Knowledge and Practice of the Breast SelfExam on Students from a Public University in Lima. Archives in Cancer Research. 2016;4(3). https://doi. org/10.21767/2254-6081.1000102

11. Gilani S, Khurram M, Mazhar T, et al. Knowledge, attitude and practice of a Pakistani female cohort towards breast cancer. J Pak Med Assoc. 2010;60:205.

12. Ishaaque $\mathrm{S}$, Gopalamenon N. Knowledge attitude practice on breast self-examination in a rural area in North Kerala. International Journal Of Community Medicine And Public Health. 201904 27;6(5):2069. https://doi. org/10.18203/2394-6040.ijcmph20191820

13. Yoo B, Choi K, Jung K, Jun J. Awareness and Practice of Breast Self-examination among Korean Women: Results from a Nationwide Survey. Asian Pacific Journal of Cancer Prevention. 201201 31;13(1):123-125. https://doi. org/10.7314/apjcp.2012.13.1.123

14. Erdem Ö, Toktaş İ. Knowledge, Attitudes, and Behaviors about Breast Self-Examination and Mammography among Female Primary Healthcare Workers in Diyarbakır, Turkey. BioMed Research International. 2016;2016:1-6. https://doi. org/10.1155/2016/6490156

15. Gore C, Kalliguddi S, Sharma S. Knowledge, attitude, and practice of breast self-examination amongst female IT professionals in Silicon Valley of India. Journal of Family Medicine and Primary Care. 2019;8(2):568. https://doi. org/10.4103/jfmpc.jfmpc_315_18

16. Taşçı A, Usta Y. Comparison of knowledge and practices of breast self-examination (BSE): a pilot study in Turkey. Asian Pac J Cancer Prev. 2010;11:1417-20.

17. Pengpid S, Peltzer K. Knowledge, Attitude and Practice of Breast Self-examination Among Female University Students from 24 Low, Middle Income and Emerging Economy Countries. Asian Pacific Journal of Cancer Prevention. 2014 Nov 06;15(20):8637-8640. https://doi.org/10.7314/ apjcp.2014.15.20.8637

18. Carelli I, Pompei LM, Mattos CS, Ferreira HG, Pescuma R, Fernandes CE, Peixoto S. Knowledge, attitude and practice of breast self-examination in a female population of metropolitan São Paulo. The Breast. 2008 06;17(3):270-274. https://doi.org/10.1016/j.breast.2007.10.010

19. Moser K, Patnick J, Beral V. Do women know that the risk of breast cancer increases with age?. Br J Gen Pract. 2007;57:404-6.

20. Parsa P, Kandiah M, Rahman H, Zulkefli N. Barriers for breast cancer screening among Asian women: a mini literature review. Asian Pac J Cancer Prev. 2006;7:509-14.

21. Huguley CM, Brown RL. The value of breast selfexamination. Cancer. 198103 01;47(5):989-995. https:// doi.org/10.1002/1097-0142(19810301)47:5<989::aidcncr2820470530>3.0.co;2-v

22. Muhammad Sani A, Labaran Yau S. Relationship between knowledge and practice of breast self-examination among female workers in Sokoto, Nigeria. Obstetrics \& Gynecology International Journal. 201805 07;9(3). https:// doi.org/10.15406/ogij.2018.09.00323

23. Alwan NA, Al-Diwan JK, Al-Attar WM, Eliessa RA. Knowledge, attitude \& practice towards breast cancer \& breast self examination in Kirkuk University, Iraq. Asian Pacific Journal of Reproduction. 2012 Dec;1(4):308-311. https://doi.org/10.1016/s2305-0500(13)60098-6

24. Alazmi SF, AlkhabbazA, Almutawa HA, Ismaiel AE, Makboul G, El-Shazly MK. Practicing breast self-examination among women attending primary health care in Kuwait. Alexandria Journal of Medicine. 201309 01;49(3):281-286. https://doi. org/10.1016/j.ajme.2012.08.009

25. Opoku S, Benwell M, Yarney J. Knowledge, attitudes, beliefs, behaviour and breast cancer screening practices in Ghana. West Africa. Pan Afr Med J. 2012;11:28.

26. Breast Cancer Knowledge and Breast Self-Examination Practices Among Female University Students in Kampala, Uganda: A Descriptive Study. Oman Medical Journal. 2016 03 13;31(2):129-134. https://doi.org/10.5001/omj.2016.25

27. Ibnawadh S, Alawad M, Alharbi S, et al. Knowledge, attitude, and practice of breast self-examination among females in medical and non-medical colleges in Qassim University. Journal of health specialities. 2017;5:219-24.

28. Doshi D, Kulkarni S, Reddy B, Karunakar P. Breast selfexamination: Knowledge, attitude, and practice among female dental students in Hyderabad city, India. Indian Journal of Palliative Care. 2012;18(1):68. https://doi. org/10.4103/0973-1075.97476

29. Noroozi A, Tahmasebi R. Factors influencing breast cancer screening behavior among Iranian women. Asian Pac J Cancer Prev. 2011;12:1239-44.

30. Budden L. Young Women's Breast Self-Examination Knowledge and Practice. Journal of Community Health Nursing. 1995 03;12(1):23-32. https://doi.org/10.1207/ s15327655jchn1201_3

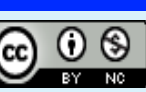

This work is licensed under a Creative Commons AttributionNon Commercial 4.0 International License. 